\title{
IDENTIFICACIÓN DE Thrips palmi Karny (THYSANOPTERA: THRIPIDAE) EN CULTIVOS DE CUCURBITÁCEAS EN PANAMÁ ${ }^{1}$
}

\author{
José Ángel Herrera-Vásquez², Anovel Amet Barba-Alvarado
}

\begin{abstract}
RESUMEN
Identificación de Thrips palmi Karny (Thysanoptera: Thripidae) en cultivos de cucurbitáceas en Panamá. El objetivo de este trabajo fue la identificación morfológica y molecular de T. palmi en cultivos de cucurbitáceas en Panamá. Los especímenes fueron colectados en las provincias de Los Santos, Herrera, Coclé, Veraguas y Chiriquí, del 17 de febrero de 2009 al 17 de agosto de 2010. La identificación de los insectos fue realizada en el Laboratorio de Protección Vegetal (LPV), del Centro de Investigación Agropecuaria Central (CIAC), del Instituto de Investigación Agropecuaria de Panamá (IDIAP), ubicado en Los Canelos, distrito de Santa María, provincia de Herrera, Panamá. Los especímenes fueron identificados mediante morfología utilizando claves taxonómicas. Se utilizó la reacción en cadena de la polimerasa (PCR) con cebadores específicos de T. palmi, los cuales amplifican el gen mitocondrial de la citocromo oxidasa subunidad I (mtCOI). Se obtuvieron amplicones (productos de PCR) del tamaño esperado (220-pb) correspondientes a $T$. palmi. Adicionalmente, un producto amplificado fue purificado y secuenciado. Para verificar la identidad del insecto, la secuencia obtenida fue analizada con ayuda del Instrumento de Búsqueda de Alineamientos Locales Básicos (BLAST) y comparada con secuencias de referencia del Centro Nacional para la Información Biotecnológica (NCBI).
\end{abstract}

Palabras clave: claves taxonómicas, cebadores específicos, identificación morfológica, identificación molecular, PCR, secuenciación.

\begin{abstract}
Identification of Thrips palmi Karny (Thysanoptera: Thripidae) in cucurbit crops in Panama. The objective of this work includes the morphological and molecular identification of T. palmi in cucurbit crops in Panama. The specimens were collected from the provinces of Los Santos, Herrera, Coclé, Veraguas and Chiriquí, from February $17^{\text {th }}$ of 2009 until August $17^{\text {th }}$ of 2010. The insects identification was realized at the Laboratory of Plant Protection (LPV), of Agricultural Research Center Central (CIAC), of Agricultural Research Institute of Panama (IDIAP), located in Los Canelos, Santa María district, Herrera province, Panama. The specimens were identified by morphology using the taxonomic keys. The polymerase chain reaction (PCR) was used with T. palmi specific-primers, which amplify the mitochondrial gene cytochrome oxidase subunit I (mtCOI). Amplicons (PCR products) of the expected size (220-bp) were obtained from T. palmi. Furthermore, an amplified product was purified and sequenced. To verify the identity of the insect, the sequence obtained from it was analyzed using the Basic Local Alignment Search (BLAST) and compared with reference sequences from the National Center for Biotechnology Information (NCBI).
\end{abstract}

Key words: taxonomic keys, specific-primers, morphological identification, molecular identification, PCR, sequencing.

\footnotetext{
1 Recibido: 27 de abril, 2012. Aceptado: 1 de abril, 2013. Este trabajo se realizó como parte del proyecto "Determinación de las características básicas de la población de Thrips palmi (Thysanoptera:Thripidae) en cucurbitáceas cultivadas, con la finalidad de establecer estrategias de manejo integrado".

2 Laboratorio de Protección Vegetal (LPV), Centro de Investigación Agropecuaria Central (CIAC), Instituto de Investigación Agropecuaria de Panamá (IDIAP). Carretera Panamericana, Los Canelos-Santa María, Herrera, Panamá. Código postal 0601, Chitré, Herrera, Panamá. joshervs11@gmail.com (Autor para correspondencia), anovelbarba@gmail.com
} 


\section{INTRODUCCIÓN}

La familia Thripidae comprende 260 géneros y cerca de 1850 especies, mientras que el género Thrips contiene más de 200 especies a nivel mundial. Thrips palmi Karny (Thysanoptera: Thripidae) es una especie de plaga polífaga, especialmente de cucurbitáceas y solanáceas. Esta especie es originaria del sur de Asia, y, actualmente, se encuentra muy extendida en América Central y el Caribe. Sin embargo, se presenta de manera localizada en Norte y Sur América, África y Oceanía. Adicionalmente, se han reportado varios brotes en Holanda y un brote en Reino Unido, los cuales fueron erradicados. Por lo tanto, esta plaga no está presente en Europa (OEPP/EPPO 2006), según la literatura consultada.

En Panamá, la presencia de T. palmi se reportó en el año 2006, en un cultivo de sandía [Citrullus lanatus (Thunb.) Matsum. \& Nakai] ubicado en la localidad de Los Chicharrones, distrito de Chitré, provincia de Herrera, al suroeste de Panamá. El Ministerio de Desarrollo Agropecuario (MIDA) de Panamá, a través del resuelto Ministerial No. DAL-028 (de 18 mayo de 2006), establece una serie de medidas cuarentenarias tendientes a evitar su establecimiento a nivel nacional, declarando zonas de baja prevalencia, así como localidades libres de esta plaga, con base en la normativa vigente (MIDA 2006).

Thrips palmi causa daños significativos en cultivos hortícolas en diferentes regiones del mundo, por ejemplo, en México se reportan daños de 5 a $80 \%$ en sandía, y 50 a $90 \%$ en berenjena (Solanum melongena L.) y pepino (Cucumis sativus L.) (OIRSA 2011). Adicionalmente, esta plaga está incluida en la lista de alerta de la Organización Europea y Mediterránea de Protección a las Plantas (EPPO) (OEPP/EPPO 2006) y del Sistema de Alerta Fitosanitaria de la Organización Norteamericana de Protección a las plantas (NAPPO) (NAPPO 2004). Por lo tanto, podría causar importantes pérdidas económicas en cultivos de exportación como melón (Cucumis melo L.), sandía, zapallo (Cucurbita moschata L.), y pepino, debido a la restricción de estas hortalizas en los mercados internacionales.

Además del daño causado por T. palmi al alimentarse de las plantas, este insecto tiene la capacidad de ser un vector de diferentes especies del género Tospovirus, entre ellos, el virus de la mancha clorótica del lirio cala (Calla lily chlorotic spot virus, CCSV;
Chen et al. 2005), virus de la necrosis del brote del cacahuate (Groundnut bud necrosis virus, GBNV; Reddy et al. 1992, Lakshmi et al. 1995, Meena et al. 2005), virus de la mancha amarilla del melón (Melon yellow spot virus, MYSV; Kato et al. 2000), y el virus del moteado plateado de la sandía (Watermelon silver mottle virus, WaSMV; Iwaki et al. 1984), citados por Riley et al. (2011).

La identificación morfológica ha sido usada tradicionalmente para identificar y diferenciar T. palmi de otras especies de trips. Sin embargo, existe cierta similitud de T. palmi con otras especies, entre ellas, Thrips alatus y Thrips pallidulus (Palmer 1992). Por lo tanto, realizar un diagnóstico hasta nivel de especie es bastante difícil, ya que los caracteres utilizados en la taxonomía muchas veces se ven afectados por la manipulación de los individuos, además de la necesidad de personal capacitado y claves taxonómicas especializadas (Rugman-Jones et al. 2007, Hoddle et al. 2008, Mound et al. 2010). Estas claves tienen la limitante que solo permiten la identificación de especímenes adultos, no así estados inmaduros (huevos, larvas o pupas) (OEPP/EPPO 2006).

Las técnicas moleculares se basan en las características genotípicas de un organismo, las cuáles son estables, y las mismas pueden ser utilizadas para identificar todas las etapas del ciclo de vida del insecto (Kox et al. 2005). Por lo tanto, el empleo de estas técnicas, por ejemplo, la reacción en cadena de la polimerasa (polymerase chain reaction, PCR) en la identificación de T. palmi (incluso en estados inmaduros y en especímenes incompletos), representa una alternativa rápida y confiable que permitiría analizar simultáneamente un gran número de especímenes, por ejemplo, en los programas de control de especies de trips que han adquirido resistencia a los insecticidas (IPPC 2007, Mound y Morris 2007), citados por Rodríguez-Romero et al. (2011). Adicionalmente, la PCR podría ser empleada para detectar oportunamente T. palmi en los puertos de entrada de Panamá y evitar su re-introducción al país, debido a que este insecto por su diminuto tamaño a menudo pasa inadvertido a través del comercio de vegetales, frutas y plantas ornamentales, especialmente en sus estados inmaduros (Rodríguez-Romero et al. 2011).

El presente estudio tuvo como objetivo la identificación morfológica de T. palmi en cultivos de cucurbitáceas en Panamá, así como la identificación molecular como una alternativa de diagnóstico. 


\section{MATERIALES Y MÉTODOS}

\section{Localización geográfica del estudio}

Los trips fueron colectados en trece diferentes localidades de las provincias de Los Santos, Herrera, Coclé, Veraguas y Chiriquí (Panamá), en el periodo comprendido del 17 de febrero de 2009 al 17 de agosto de 2010 (Figura 1, Cuadro 1).

Las localidades se georeferenciaron con un GPS portátil GARMIN Etrex Legend ${ }^{\circledR}$, obteniendo datos de latitud, longitud, y altitud, los cuales se mapearon con el programa ArcGIS® v9.3 (ESRI 2008).

\section{Colecta de trips}

Se colectaron 1023 especímenes adultos de trips en distintas especies de cucurbitáceas (melón, sandía, zapallo y pepino), así como también en un cultivo de chayote [Sechium edule (Jacq) Swantz], con ayuda de aspiradores, paneles o placas blancas y mediante golpeo enérgico sobre brotes terminales y flores, debido a que en estas partes de la planta es donde se concentran estos insectos (Goldarazena et al. 2012). Posteriormente, fueron recogidos con ayuda de un pincel humedecido con alcohol al $75 \%$ o de un aspirador, y se depositaron y preservaron en viales de $2 \mathrm{ml}$ conteniendo igualmente alcohol al $75 \%$. A cada vial se le asignó un código, el cual incluía la localidad, cultivo y fecha de colecta de los insectos.

Los especímenes fueron utilizados en la identificación morfológica, y además se utilizó la identificación molecular en el caso de T. palmi, tal y como se describe a continuación.

\section{Identificación morfológica de trips}

La identificación morfológica de trips se realizó en el Laboratorio de Protección Vegetal (LPV) del Centro de Investigación Agropecuaria Central (CIAC) del Instituto de Investigación Agropecuaria de Panamá (IDIAP), ubicado en el corregimiento de Los Canelos, distrito de Santa María, provincia de Herrera, Panamá.

Los insectos fueron observados en un estereomicroscopio Motic ${ }^{\circledR}$ SMZ-168, con aumento de 40X y un duplicador de $2 \mathrm{X}$, con la finalidad de separar preliminarmente Thrips spp. de Frankliniella spp. Seguidamente, para determinar la especie se realizó el montaje en láminas fijas siguiendo la metodología propuesta por Mound y Kibby (1998), la cual consiste en colocar inicialmente los especímenes en una solución de $\mathrm{NaOH}$ al $10 \%$ durante 60 minutos y, posteriormente, tratar los insectos con un gradiente de alcoholes de 70 a 100\%. A continuación, en una gota del medio de montaje (Euparal o bálsamo del Canadá) y con ayuda de un microalfiler, se extendieron las alas y se

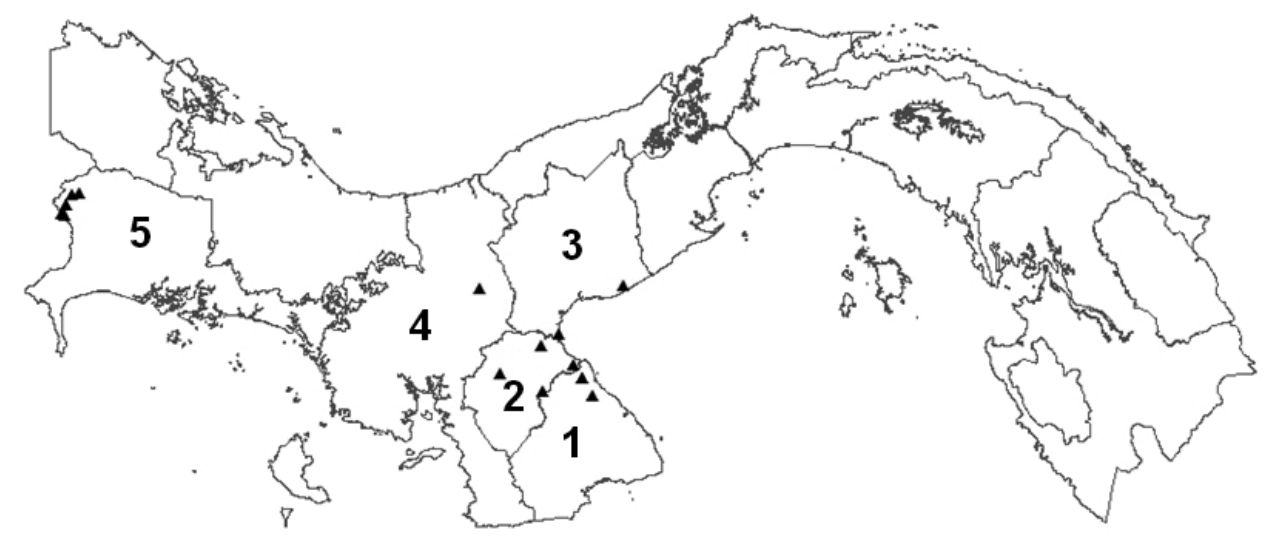

Figura 1. Localidades (indicadas con un triángulo) donde se colectaron los trips en cultivos de cucurbitáceas en Panamá. Periodo 2009-2010.

Los números 1, 2, 3, 4, y 5, corresponden a las provincias de Los Santos, Herrera, Coclé, Veraguas y Chiriquí, respectivamente. 
Cuadro 1. Localidades donde se reporta la presencia de Thrips palmi y Frankliniella spp. en cucurbitáceas en Panamá. Periodo 2009-2010.

\begin{tabular}{|c|c|c|c|c|c|c|c|c|c|c|}
\hline \multirow[t]{2}{*}{ Provincia } & \multirow[t]{2}{*}{ Localidad } & \multirow[t]{2}{*}{ Cultivo } & \multirow{2}{*}{$\begin{array}{l}\text { No. de } \\
\text { especí- } \\
\text { menes }\end{array}$} & \multicolumn{2}{|c|}{$\begin{array}{c}T . \\
\text { palmi }\end{array}$} & \multirow{2}{*}{$\begin{array}{c}\begin{array}{c}\text { Frankliniella } \\
\text { spp. }\end{array} \\
\text { Morfología }\end{array}$} & \multirow[t]{2}{*}{ Latitud } & \multirow[t]{2}{*}{ Longitud } & \multirow[t]{2}{*}{$\begin{array}{l}\text { Altitud } \\
\text { (msnm) }\end{array}$} & \multirow[t]{2}{*}{$\begin{array}{c}\text { Fecha de } \\
\text { colecta }\end{array}$} \\
\hline & & & & Morfología & PCR & & & & & \\
\hline Los Santos & Chumajal & Sandía & 24 & 7 & 6 & 11 & 749'41" & $80^{\circ} 19^{\prime} 50^{\prime \prime}$ & 44 & $17-2-2009$ \\
\hline Los Santos & Ejido & Melón & 410 & 18 & 16 & 376 & 7०54’35"' & $80^{\circ} 22^{\prime} 30^{\prime \prime}$ & 34 & $31-3-2009$ \\
\hline Los Santos & Ejido & Sandía & 45 & 13 & 5 & 27 & $7^{\circ} 54^{\prime} 22^{\prime \prime}$ & $80^{\circ} 22^{\prime} 14^{\prime \prime}$ & 32 & 31-3-2009 \\
\hline Herrera & Ocú & Melón & 15 & 5 & 0 & 10 & $7^{\circ} 55^{\prime} 52^{\prime \prime}$ & $80^{\circ} 46^{\prime} 29^{\prime \prime}$ & 17 & 3-4-2009 \\
\hline Herrera & Correa & Melón & 95 & 24 & 30 & 41 & $8^{\circ} 4^{\prime} 8^{\prime \prime}$ & $80^{\circ} 34^{\prime} 29^{\prime \prime}$ & 2 & 27-8-2009 \\
\hline Herrera & La Concepción & Sandía & 47 & 9 & 31 & 7 & 758’37”' & $80^{\circ} 25^{\prime} 25^{\prime \prime}$ & 20 & $17-8-2010$ \\
\hline Herrera & El Ciruelito & Sandía & 37 & 10 & 27 & 0 & 751'9’' & $80^{\circ} 34^{\prime} 2^{\prime \prime}$ & 91 & $17-8-2010$ \\
\hline Herrera & La Arena & Zapallo & 41 & 13 & 20 & 8 & $8^{\circ} 7^{\prime} 12^{\prime \prime}$ & $80^{\circ} 29^{\prime} 26^{\prime \prime}$ & 25 & $17-8-2010$ \\
\hline Coclé & Río Hato & Sandía & 9 & 0 & 0 & 9 & $8^{\circ} 21^{\prime} 25^{\prime \prime}$ & $80^{\circ} 10^{\prime} 46^{\prime \prime}$ & 17 & $6-6-2009$ \\
\hline Veraguas & Calobre & Sandía & 242 & 5 & 0 & 237 & $8^{\circ} 20^{\prime} 15^{\prime \prime}$ & $80^{\circ} 52^{\prime} 20^{\prime \prime}$ & 140 & $17-2-2009$ \\
\hline Chiriquí & Monte Lirio & Pepino & 13 & 7 & 6 & 0 & $8^{\circ} 47^{\prime} 00 "$ & $82^{\circ} 49^{\prime} 70^{\prime \prime}$ & 872 & $6-5-2009$ \\
\hline Chiriquí & San Antonio & Pepino & 17 & 7 & 10 & 0 & 8०47’29"' & $82^{\circ} 47^{\prime} 43^{\prime \prime}$ & 916 & $6-5-2009$ \\
\hline Chiriquí & Bajo Chiriquí & Pepino & 16 & 11 & 5 & 0 & 8'44'6”' & $82^{\circ} 51^{\prime} 13^{\prime \prime}$ & 882 & $5-6-2009$ \\
\hline Chiriquí & Los Planes & Chayote & 6 & 0 & 0 & 6 & $8^{\circ} 41^{\prime} 6$ "' & $82^{\circ} 51^{\prime} 43^{\prime \prime}$ & 880 & 6-6-2009 \\
\hline \multirow[t]{2}{*}{ Chiriquí } & Los Planes & Pepino & 6 & 2 & 0 & 4 & $8^{\circ} 41^{\prime} 47^{\prime \prime}$ & $82^{\circ} 52^{\prime} 27^{\prime \prime}$ & 911 & $6-6-2009$ \\
\hline & & & 1023 & 131 & 156 & 736 & & & & \\
\hline
\end{tabular}

enderezaron las antenas, dejando visible el pronoto. Inmediatamente, las láminas se colocaron en un horno a una temperatura aproximada entre 35 y $40^{\circ} \mathrm{C}$ durante seis horas. Las observaciones se realizaron con ayuda de un estereomicroscopio Motic ${ }^{\circledR}$ SMZ-168, con aumento de 40 a 200X; luego de seis semanas, los preparados se sellaron de manera permanente con esmalte para uñas.

Para la identificación de la especie de Thrips y Frankliniella se utilizaron las claves taxonómicas de Palmer et al. (1989), Mound y Marullo (1996) y Moritz et al. (2004), mientras que para T. palmi se utilizó además el protocolo de diagnóstico para las plagas reglamentadas, Anexo 01 de la NIMF 27 (IPPC 2007). Una vez identificados los insectos, se fotografiaron cada uno de los caracteres morfológicos al microscopio Motic ${ }^{\circledR}$ BA300, con ayuda de una cámara digital Moticam 2300 y el software Motic Images Plus v2.0.

\section{Identificación molecular de T. palmi}

Los especímenes de Thrips spp. procedentes de todos los cultivos de cucurbitáceas y de la mayoría de las localidades geográficas donde este género fue encontrado, y que no fueron utilizados en la identificación morfológica debido a que estaban incompletos, probablemente debido a la manipulación de los mismos durante la colecta, se utilizaron en la identificación molecular de T. palmi como una alternativa de diagnóstico a la identificación morfológica, tal y como se describe a continuación.

\section{Extracción de ADN}

El ADN de Thrips spp. se obtuvo a partir de especímenes colocados de manera individual en tubos de 1,5 ml. Estos insectos fueron macerados con ayuda 
de un micropistilo, usando el Wizard® Genomic DNA Purification kit (Promega, Madison, WI, USA). Adicionalmente, se procedió a extraer el ADN de especímenes de Frankliniella spp. (control negativo) provenientes de este estudio, siguiendo el mismo procedimiento descrito previamente para Thrips spp. Los extractos se almacenaron a $-30^{\circ} \mathrm{C}$ para su posterior análisis por PCR.

\section{Amplificación por PCR}

La identificación molecular de T. palmi se realizó mediante PCR (Cuadro 1), utilizando una pareja de cebadores específicos de esta especie, R4 (5`-CCC TCT TAA TTA TGG GTT TAT A-3') y F5 (5’-CAC AAA TAA TCT TAG TTT TTC TCT T'-3), los cuales amplifican un fragmento de $220-\mathrm{pb}$, correspondiente al gen mitocondrial de la citocromo oxidasa subunidad I (COI) (Kox et al. 2005).

Las concentraciones finales de cada reactivo fueron las siguientes: 1x tampón PCR, 1,5 $\mathrm{mM} \mathrm{MgCl}^{+2}$, 0,2 $\mathrm{mM}$ dNTPs (Promega), 0,76 $\mu \mathrm{M}$ de cada cebador, una unidad de Taq DNA Polimerasa (Invitrogen, Brasil), $1 \mu 1$ de cada extracto de ADN, y agua ultrapura estéril hasta alcanzar un volumen de $50 \mu 1$ (Kox et al. 2005). Posteriormente, el ADN de T. palmi se amplificó con ayuda de un termociclador Q-cycler (Quanta Biotech), el cual se programó para llevar a cabo un ciclo inicial de desnaturalización a $94^{\circ} \mathrm{C}$ durante un minuto, seguido por 40 ciclos de desnaturalización a $94^{\circ} \mathrm{C}$ durante quince segundos, hibridación a $55^{\circ} \mathrm{C}$ durante 30 segundos, y extensión a $72^{\circ} \mathrm{C}$ durante 45 segundos. Adicionalmente, se llevó a cabo un ciclo de extensión final a $72^{\circ} \mathrm{C}$ durante diez minutos, este último con la finalidad de sintetizar todos los fragmentos que posiblemente quedaron incompletos, seguido de un paso de enfriamiento a $10^{\circ} \mathrm{C}$ hasta que las muestras fueron recuperadas. Como controles negativos, se utilizaron extractos de ADN de Frankliniella spp., así como agua ultrapura estéril, los cuales se analizaron bajo las mismas condiciones descritas anteriormente para T. palmi.

Los productos amplificados por PCR $(8 \mu \mathrm{l})$, se sometieron a electroforesis en un gel de agarosa al 1,5\% en tampón TBE 1x ( $89 \mathrm{mM}$ Tris, $89 \mathrm{mM}$ ácido bórico, $2 \mathrm{mM}$ EDTA, pH 8,3), a 56 voltios durante aproximadamente tres horas. A continuación, los productos se tiñeron con bromuro de etidio $(0,2 \mu \mathrm{g} / \mathrm{ml})$, y se visualizaron y fotografiaron bajo luz ultravioleta. El tamaño de los fragmentos amplificados se determinó por comparación con un marcador de peso molecular de 100 pb DNA Molecular Weight Ladders (Amresco, Solon, OH, USA).

\section{Secuenciación y análisis}

Para confirmar la identidad de T. palmi, un producto de PCR fue purificado con ayuda del High Pure PCR Product Purificación Kit (Roche Diagnostics $\mathrm{GmbH}$, Mannheim, Alemania). Posteriormente, este producto fue cuantificado por fluorometría con ayuda del Quant-IT ${ }^{\mathrm{TM}}$ dsDNA BR Assay Kits, en un fluorómetro Qubit ${ }^{\mathrm{TM}}$ (Invitrogen, Eugene, OR, USA), en el Instituto de Investigaciones Científicas y Servicios de Alta Tecnología (INDICASAT), Panamá. Seguidamente, el producto fue secuenciado en ambas direcciones con ayuda del BigDye Terminator Cycle Sequencing Kit v3.0, en un analizador genético ABI Prism 3130XL (Applied Biosystems, Foster City, CA, USA), en el Instituto Smithsonian de Investigaciones Tropicales (Smithsonian Tropical Research Institute, STRI), Panamá.

La secuencia de nucleótidos obtenida fue comparada con ayuda del Instrumento de Búsqueda de Alineamientos Locales Básicos (Basic Local Alignment Search Tool, BLAST) (Altschul et al. 1997), con secuencias de T. palmi disponibles en la base de datos del Centro Nacional para la Información Biotecnológica (National Center for Biotechnology Information, NCBI).

\section{RESULTADOS Y DISCUSIÓN}

\section{Descripción de caracteres morfológicos de T. palmi}

La identificación y diferenciación de T. palmi de otras especies conocidas del género Thrips, se llevó a cabo según los caracteres morfológicos observados en este estudio, los cuales indicamos a continuación. Uno de los caracteres típicos de este género es la presencia de dos pares de setas ocelares. En el caso de T. palmi, esta especie presentó setas ocelares gruesas y negruzcas (Figura 2A), ubicadas fuera del triángulo ocelar y la línea exterior tangente, mientras que su cuerpo era amarillo claro sin manchas de color grisáceo o pardo. Adicionalmente, mostró antenas de siete segmentos. El tercer y cuarto poseían un cono sensorial bifurcado, el VI medía 42-48 $\mu \mathrm{m}$ de longitud, y los segmentos 


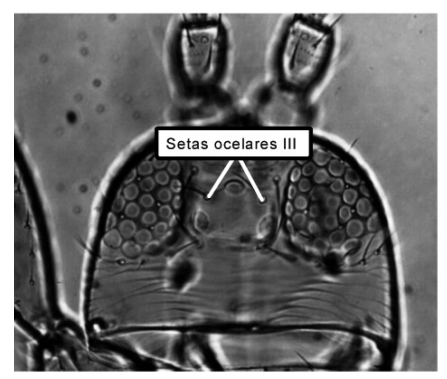

Figura 2A. Triángulo ocelar: setas ocelares III, con sus bases situadas fuera de la línea imaginaria del triángulo ocelar.

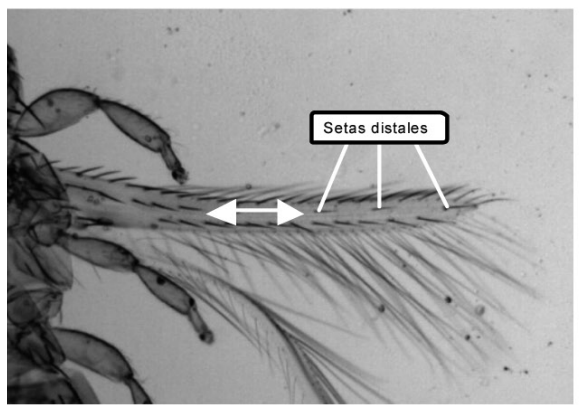

Figura 2D. Ala anterior: primera vena con una hilera de setas, con espacios en la mitad distal.
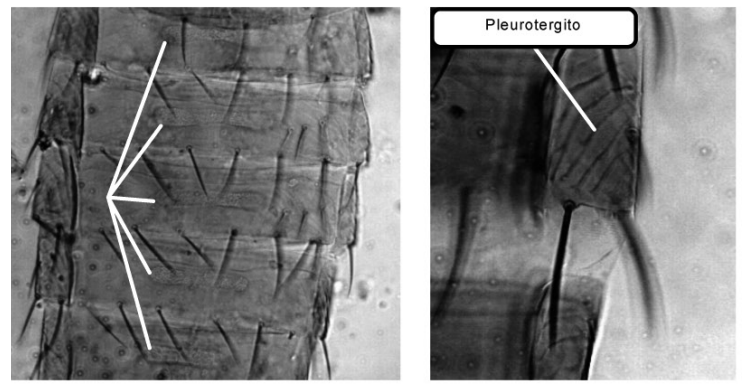

Figura 2G. Esternitos del ma- Figura 2H. Pleurotergito cho: aéreas glandulares transversales en esternitos III a VII. (derecha). abdominal: promicrotrichas, setas secunda-

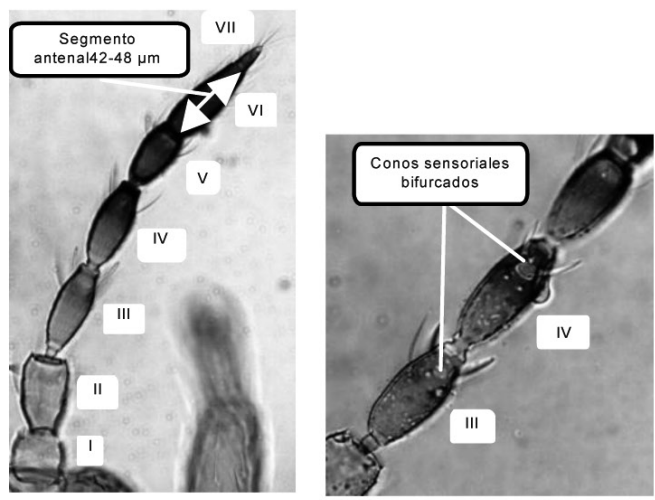

Figura 2B. Antena de siete segmentos: segmento V de 42-48 $\mu \mathrm{m}$, segmentos de IV a VII de color oscuro (izquierda), segmentos III y IV con conos sensoriales bifurcados

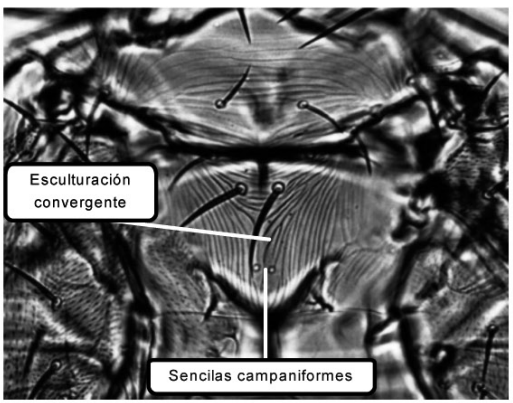

Figura 2E. Metanoto: un par de sencilas campaniformes, y esculturación convergente posterior.
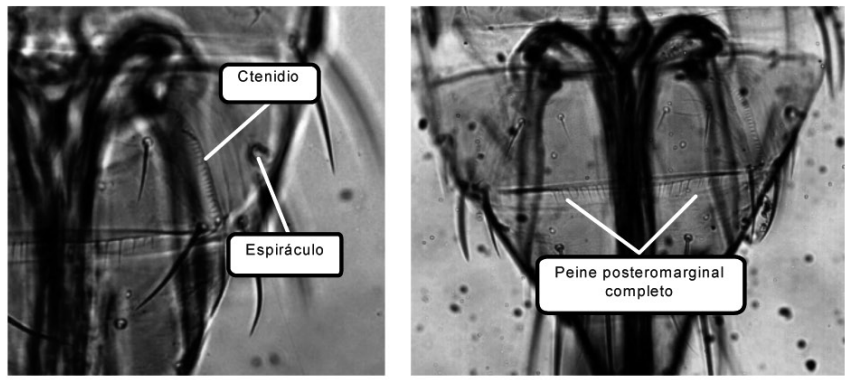

Figura 2I. Tergito abdominal VIII: ctenidio lateral posterior a la abertura del espiráculo (izquierda), peine posteromarginal completo de microtrichias (derecha).

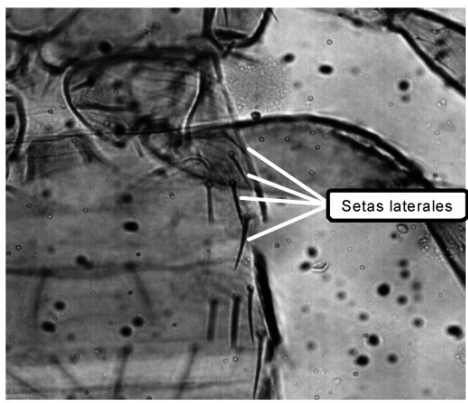

Figura 2F. Tergito abdominal II: cuatro setas laterales. rias ausentes. 
antenales IV-VII eran de color oscuro (Figura 2B). En el caso del género Thrips, el número de segmentos antenales es de 7-8. Por otro lado, el pronoto de esta especie presentó dos pares de setas posteroangulares (Figura 2C). El ala anterior, presentó una primera vena con una hilera de setas, con espacios en la mitad distal (Figura 2D). El metanoto de este insecto, mostró una estría mesal y, por lo general, convergente, con un par de poros metanotal (sencilas campaniformes) (Figura 2E). Por otro lado, el tergito abdominal II con cuatro setas laterales (Figura 2F). En relación a los especímenes machos, los esternitos III-VII tuvieron un área glandular transversal (Figura 2G). En cuanto a los pleurotergitos, estos se observaron sin setas (Figura $2 \mathrm{H})$, mientras que el tergito adbominal VIII, presentó ctenidio abdominal posterior al espiráculo, y peine completo (Figura 2I).

\section{Identificación molecular y análisis de secuencias de T. palmi}

La identificación molecular de T. palmi, se realizó mediante PCR, obteniéndose el amplicón (producto de PCR) del tamaño esperado (220-pb), a partir de todos los especímenes ubicados preliminarmente dentro del género Thrips spp., mientras que dicho amplicón no fue observado en los controles negativos (Frankliniella spp. y agua ultrapura estéril) (Figura 3). Estos resultados fueron confirmados mediante secuenciación de ADN.

La secuencia de T. palmi obtenida en este estudio (TTTTTTCTCTCCATTTAGCTGGGGTATCCTCAATTTTAGGAGCATTAAATTTCATCACTACAATTTTAAATTTAAAAAATAAAAATCTTTCAAGAGAAAAACTAAG), se comparó con secuencias de este insecto procedentes de diferentes partes del mundo, publicadas en la base de datos del NCBI y en Glover $e t$ al. (2010): número de accesión de GenBank FM956397 (Tailandia), AM932004 (República Dominicana), FM956392 (India) y AM932037 (Japón). En este sentido, la secuencia de T. palmi de Panamá presentó 100\% de identidad en una porción del gen (mtCOI), en comparación con las secuencias de esta especie indicadas previamente, confirmando la identidad del insecto.

La secuencia de T. palmi de Panamá no fue publicada en la base de datos del NCBI, debido a que una de las políticas de dicho centro consiste en no publicar secuencias <200-pb. Por el contrario, las de T. palmi indicadas anteriormente, presentaron 458-pb; por lo

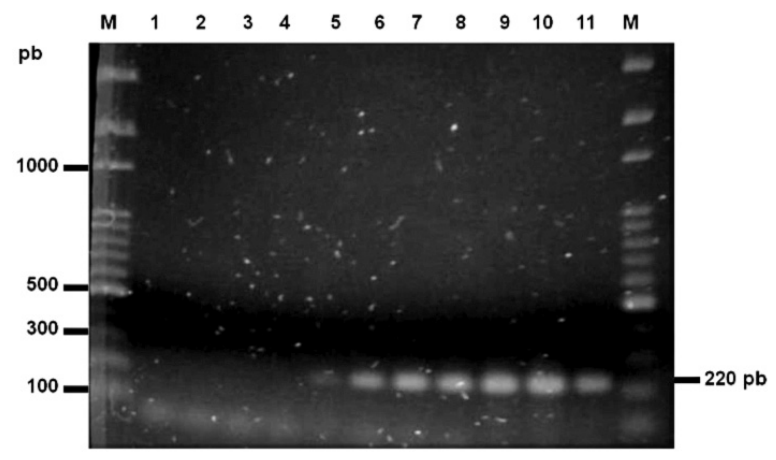

Figura 3. Electroforesis en gel de agarosa de los productos de PCR del ADN de los especímenes de Thrips palmi colectados en cucurbitáceas en Panamá (periodo 2009-2010) amplificados por PCR.

Línea 1, agua ultrapura estéril (control negativo); Líneas 2 a 4 , Frankliniella spp. (control negativo); Líneas 5 a 11, T. palmi; M, Marcador de peso molecular de 100-pb DNA Molecular Weight Ladders (Amresco, Solon, OH, USA).

tanto, estas fueron publicadas en la base de datos del NCBI. Es importante indicar que las secuencias publicadas por Glover et al. (2010), fueron obtenidas con cebadores que amplifican una porción más grande del gen mtCOI. Por lo tanto, dichas secuencias tienen un mayor número de bases en comparación con la de $T$. palmi de Panamá.

\section{Distribución geográfica de T.palmi en Panamá}

Doscientos ochenta y siete especímenes $(28,05 \%$; $\mathrm{n}=1023$ ) fueron identificados como T. palmi mediante morfología (131 especímenes) y PCR (156 especímenes), y los mismos procedían de diferentes localidades de las provincias de Los Santos, Herrera, Veraguas y Chiriquí (Cuadro 1). En este sentido, T. palmi había sido reportado previamente en una localidad de la provincia de Herrera (MIDA 2006). Por lo tanto, este es el primer reporte de la presencia de esta plaga en las provincias de Los Santos, Veraguas, y Chiriquí, según la literatura consultada. Este insecto no fue encontrado en la provincia de Coclé, debido probablemente al reducido número de especímenes analizados en esta región (Cuadro 1).

Recientemente, Goldarazena et al. (2012) reportaron también la presencia de T. palmi en Panamá. No obstante, estos autores no indican las localidades y 
provincias donde identificaron esta plaga. Por lo tanto, nuestro estudio es el primero que describe en detalle la distribución geográfica de T. palmi en Panamá, según la literatura consultada, y ayudará sin duda alguna a la toma de decisiones para tratar de controlar las poblaciones de esta plaga en las localidades donde ha sido reportada. Adicionalmente, permitirá implementar medidas cuarentenarias internas para reducir el riesgo de introducción de este insecto en áreas donde todavía no se ha reportado su presencia. Thrips palmi se encontró desde los 2 hasta los $916 \mathrm{msnm}$ (Cuadro 1). Adicionalmente, el 17,88\% ( $\mathrm{n}=520)$ de los especímenes colectados en cultivos de melón fueron identificados como T. palmi, $27,97 \%(\mathrm{n}=404)$ en sandía, 80,49\% $(\mathrm{n}=41)$ en zapallo, y $92,31 \%(\mathrm{n}=52)$ en pepino. T. palmi fue encontrado en un cultivo de sandía ubicado en las inmediaciones de una planta empacadora de cucurbitáceas en la localidad de La Concepción, en la provincia de Herrera. Por lo tanto, esta situación podría poner en riesgo las exportaciones de cucurbitáceas de Panamá. Este insecto no se encontró en el cultivo de chayote (Cuadro 1). Goldarazena et al. (2012) identificaron $T$. palmi en cucurbitáceas y en malezas asociadas (Amaranthus spp.) y en maíz (Zea mays L.) de Panamá, pero estos autores no indican las especies de cucurbitáceas donde encontraron este insecto.

Se identificaron como Frankliniella spp. 736 especímenes $(71,95 \% ; n=1023)$ (Cuadro 1). No se realizó la identificación, a nivel de especie, debido a que este no era el objetivo del trabajo.

\section{AGRADECIMIENTOS}

Agradecemos al Ing. M.Sc. Vidal Aguilera (LPVCIAC-IDIAP, Panamá), Dr. Abby Guerra (Grupo CALESA, Panamá) y al Ing. Amed Arcia (Dirección Nacional de Sanidad Vegetal-DNSV-MIDA, Panamá), por el apoyo inicial en la identificación molecular de T. palmi, a Armando Gutiérrez por su apoyo en el montaje y las fotografías de los caracteres morfológicos de los insectos, y al Ing. M.Sc. Lweonel Agudo (Laboratorio de Suelo-CIAC-IDIAP, Panamá) por su apoyo en el mapeo de los datos de latitud y longitud correspondientes a las localidades georeferenciadas. Igualmente, agradecemos a la DNSV-MIDA, Panamá, en especial al Ing. M.Sc. Efraín de Gracia (q.e.p.d), Ing. M.Sc. Randy Atencio, Ing. Arquímedes Calderón y Agr. Jorge Ramos, por su colaboración en las colectas de trips en los cultivos de cucurbitáceas en Panamá. Agradecemos también a los Drs. Joseph Funderburk (Universidad de Florida, USA), Arturo Goldarazena (Instituto Neiker, España) y Moraima Suris (Centro Nacional de Sanidad AgropecuariaCENSA, Cuba), por enriquecer nuestros conocimientos en relación a la identificación morfológica de T. palmi, así como a la Dra. Carmenza Spadafora (Instituto de Investigaciones Científicas y Servicios de Alta Tecnología-INDICASAT, Panamá), por su apoyo en la purificación y cuantificación de los productos de PCR de T. palmi. De igual forma, agradecemos a la Ing. MSc. Cecil Montemayor (LPV-CIAC-IDIAP, Panamá) por la revisión y corrección inicial del Abstract presentado en este artículo. Este trabajo se realizó como parte del Proyecto I+D FID-07-0702007, financiado por la Secretaría Nacional de Ciencia, Tecnología e Innovación (SENACYT) de Panamá.

\section{LITERATURA CITADA}

Altschul, SF; Madden, TL; Schaffer, AA; Zhang, J; Zhang, Z; Miller, W; Lipman, DJ. 1997. Gapped BLAST and PSI-BLAST: a new generation of protein database search programs. Nucleic Acids Research 25:33893402.

Chen, CC; Chen, TC; Lin, YH; Yeh, SD; Hsu, HT. 2005. A chlorotic spot disease on calla lilies (Zantedeschia spp.) is caused by a Tospovirus serologically but distantly related to Watermelon silver mottle virus. Plant Disease 89:440-445.

ESRI (Environmental Systems Research Institute). 2008. ArcMap version 9.3. Redlands, California, USA. 435 p.

Glover, RH; Collins, DW; Walsh, K; Boonham, N. 2010. Assessment of loci for DNA barcoding in the genus Thrips (Thysanoptera:Thripidae). Molecular Ecology Resources 10:51-59.

Goldarazena, A; Gattesco, F; Atencio, R; Korytowski, C. 2012. An updated checklist of the Thysanoptera of Panama with comments on host associations. Check List 8:1232-1247.

Hoddle, MS; Heraty, JM; Rugman-Jones, PF; Mound, LA; Stouthamer, R. 2008. Relationships among species of Scirtothrips (Thysanoptera: Thripidae, Thripinae) using molecular and morphological data. Annals of the Entomological Society of America 101:491-500. 
IPPC (International Plant Protection Convention). 2007. Normas Internacionales para medidas fitosanitarias: Protocolos de diagnóstico para las plagas reglamentadas. Anexo 01 (2010) de la NIMF 27 (2006) Thrips palmi Karny. 22 p.

Iwaki, M; Honda, Y; Hanada, K; Tochihara, H; Yonaha, T; Hokama, K; Yokoyama, T. 1984. Silver mottle disease of watermelon caused by Tomato spotted wilt virus. Plant Disease 68:1006-1008.

Kato, K; Hanada, K; Kameya-Iwaki, M. 2000. Melon yellow spot virus: a distinct species of the genus Tospovirus isolated from melon. Phytopathology 90:422-426.

Kox, LFF; van den Beld, HE; Zijlstra, C; Vierbergen, G. 2005. Real-time PCR assay for the identification of Thrips palmi. Bulletin OEPP/EPPO Bulletin 35:141-148.

Lakshmi, KV; Wightman, JA; Reddy, DVR; Rao, GVR; Buiel, AAM; Reddy, DDR. 1995. Transmission of Peanut bud necrosis virus by Thrips palmi in India. In Parker, BL; Skinner, M; Lewis, T. eds. Thrips Biology and Management. Plenum, New York, USA. p. 179-184.

Meena, RL; Venkatesan, TRS; Mohankumar, S. 2005. Molecular characterization of Tospovirus transmitting thrips populations from India. American Journal of Biochemistry and Biotechnology 1:167-172.

MIDA (Ministerio de Desarrollo Agropecuario). 2006. Ministerio de Desarrollo Agropecuario, Resuelto No. DAL-028 (De 18 de mayo de 2006), "Por medio del cual se declara a Thrips palmi bajo control oficial fitosanitario en todo el territorio nacional. Gaceta Oficial No. 25272, Panamá, República de Panamá. p. 9.

Moritz, G; Mound, LA; Morris, DC; Goldarazena, A. 2004. Pest thrips of the world, visual and molecular identification of pest thrips. CD ROM. CBIT, Brisbane, Australia. 70 p.

Mound, LA; Kibby, G. 1998. Thysanoptera: An Identification Guide. 2 ed. CAB International, Wallingford, UK. 70 p.

Mound, LA; Marullo, R. 1996. The thrips of Central and South America: an introduction. International Memoirs on Entomology 6:1-488.

Mound, LA; Morris, D. 2007. The insect order Thysanoptera: classification versus systematics. Zootaxa 1668:395-411.

Mound, LA; Wheeler, GS; Williams, DA. 2010. Resolving cryptic species with morphology and DNA; thrips as a potential biocontrol agent of Brazilian peppertree, with a new species and overview of Pseudophilothrips (Thysanoptera). Zootaxa 2432:59-68.

NAPPO (North American Plant Protection Organization). 2004. Sistema de alerta fitosanitaria de la Organización Norteamericana de Protección a las Plantas (en línea). Consultado 4 sep. 2012. Disponible en http://www. pestalert.org/

OEPP/EPPO (European and Mediterranean Plant Protection Organization). 2006. Diagnostic protocols for regulated pest PM 7/3 (2). Thrips palmi. Bulletin OEPP/EPPO Bulletin 36:89-94.

OIRSA (Organismo Internacional Regional de Sanidad Agropecuaria). 2011. Guía didáctica sobre plagas y enfermedades de importancia económica en la región del OIRSA (en línea). Consultado 11 oct. 2011. Disponible en http://www.oirsa.org/portal/ documents/GUIA_DIDACTICA_PLAGAS_Y_ ENFERMEDADES.pdf

Palmer, JM. 1992. Thrips (Thysanoptera) from Pakistan to the Pacific: a review. The Bulletin of the British Museum (Natural History). Entomology Series 61:176.

Palmer, J; Mound, LA; Heaume, GJ. 1989. IIE Guides to insects of importance to man. In Betts, CR. ed. Thysanoptera. CAB International, Wallingford, United Kingdom. 73 p.

Reddy, DVR; Ratna, ASM; Sudarshana, R; Poul, F; Kumar, IK. 1992. Serological relationships and purification of bud necrosis virus, a Tospovirus occurring in peanut (Arachis hypogaea L.) in India. Annals of Applied Biology 120:279-286.

Riley, DG; Joseph, SV; Srinivasan, R; Diffie, S. 2011. Thrips vectors of tospoviruses. Journal of Integrated Pest Management 1:1-10.

Rodríguez-Romero, A; Posos Ponce, P; Peteira, B; Suris, M. 2011. Evaluación de tres protocolos de extracción de ADN en insectos del orden Thysanoptera. Revista de Protección Vegetal 26:187-190

Rugman-Jones, PF; Hoddle, MS; Stouthamer, R. 2007. Population genetics of Scirtothrips perseae: tracing the origin of a recently introduced exotic pest of Californian avocado orchards, using mitochondrial and microsatellite DNA markers. Entomologia Experimentalis et Applicata 124:101-115. 
